\title{
PROGESTINS AND THE RISK OF BREAST CANCER
}

\author{
G. Mastorakos ${ }^{1,2}$, G. Iatrakis ${ }^{3,4}$, S. Zervoudis ${ }^{3,4}$, S. Syropoulou ${ }^{2,5, *}$ \\ ${ }^{1}$ Aretaieio Hospital, ${ }^{2}$ University Kapodistrian, ${ }^{3}$ Rea Hospital, ${ }^{4}$ University West Attica of Athens, Athens, Greece, \\ ${ }^{5}$ Evaggelismos Hospital, Paphos, Cyprus
}

\begin{abstract}
Objectives. The present paper aims to investigate the effects of both progesterone and progestin treatment mainly related to the occurrence of breast cancer in women.

Materials and methods. Extensive systematic bibliographic review of Greek and International articles was conducted through the electronic databases Pubmed, Cinahl, Uptodate, and Google Scholar for the identification of articles related to progesterone, progestins and breast cancer treatment.

Results. Hormone therapy with the use of estrogen alone presents a small increased risk or does not present at all an increased risk of breast cancer. With ORs in some studies below 1.0 in current users for 3 plus years and safe option until 7 years, while in other studies the risk was increased with the ORs 1.29. However, the use of estrogen in combination with progestogens, depending on the type of progestogens, shows an increased risk of breast cancer, with the ORs to vary between $1.14-2.38$ from 3 to 5 years and is inversely proportional to the time of its use. This risk varies depending on the combination of the preparations. Other factors that are associated with breast cancer risk when receiving hormone therapy are the years that hormone therapy is taken, directly proportional to the risk. At higher risk are older women, women with low body mass index in menopause $\left(B M I<25 \mathrm{~kg} / \mathrm{m}^{2}\right)$ and women with increased mammographic breast density. Continued use of hormone therapy is associated with an increased risk for breast cancer compared to sequential. The risk became visible sooner to women who used in the past hormone therapy and were using it again. Starting hormone therapy in the immediate postmenopausal period also increased the risk for breast cancer. Hormone therapy was associated with tumors with positive estrogen and progesterone receptors, and also the lobular histological type was associated with its use. Tibolone use was associated with an increased risk.
\end{abstract}

Keywords: progesterone, progestins, breast cancer, therapy, HRT (Hormone replacement therapy), MHT (Menopause Hormone therapy).

\section{INTRODUCTION}

Today, it is well known that the most effective treatment against vasomotor symptoms $(1,2)$, urogenital atrophy and severe climacteric syndrome (3) for women of menopausal age, is the hormonal therapeutic approach (2, 4-8), which prevents long-term estrogen deficiency (3) (Table 1). According to a wealth amount of data $(5,9,10)$ from both the U.S. and Europe (9), there is an unanswered question as to whether the incidence and development of breast cancer, which can even lead to death, is correlated with the systematic used of hormone therapy with estrogen or the use of combined therapy of estrogen and progestogens during the menopause, and whether the overall risk of their use outweighs the benefits $(6,11)$ (Table 2). Women are exposed to the appearance and development of breast cancer, as it is the most common malignancy in women. It is estimated that the probability of developing breast cancer reaches $12 \%$ and from this percentage, almost half are diagnosed between the ages of 45-65 years, a period when hormonal therapy is usually prescribed and begins (4).

In the last years, Menopause Hormone Therapy (MHT) was granted to prevent chronic diseases related to old age, such as cognitive impairment and loss of bone density $(1,4,12)$ and acts beneficially in the cardiovascular system, before the onset of advanced atherosclerosis $(1,4,12,13)$. However, according to today's data, there is no clinical indication for the use of MHT in order to prevent these chronic diseases. With menopause hormone therapy having a clinical indication of prescribing only in relatively young women with mild to severe menopausal symptoms $(2,5,7,12)$. The use of hormone replacement therapy in menopausal women includes estrogen monotherapy in women without a uterus and combined hormone therapy with estrogen and progesterone/ progestins in women with intact uterus, which although is very effective in treating menopausal

*Correspondence to: Stavroula Syropoulou, E-mail: stavroula.syropoulou @gmail.com 
Table 1. Signs and symptoms of menopause (7)

\begin{tabular}{l}
\hline Central Nervous System \\
\hline Vasomotor Symptoms (Hot Flashes, Night sweats) \\
Mood Disorders (Anxiety, Depression) \\
Cognitive Function (Memory loss, Cognitive difficulties) \\
Sleep Disorders (Delayed awakening, Frequent awakening) \\
\hline Urogenital System \\
\hline Vaginal atrophy, Dyspareunia \\
Sexual Dysfunction \\
Feeling of necessity and anxiety \\
Frequent urination \\
\hline Musculoskeletal system \\
\hline Musculoskeletal pain \\
Loss of muscle mass \\
Low bone density (Osteopenia, Increased risk of fractures) \\
\hline
\end{tabular}

symptoms $(2,5,12)$, it is also associated with an increased risk of breast cancer (5). The use of combined hormone therapy is to avoid abnormal vaginal bleeding, endometrial hyperplasia and endometrial cancer. Thus, controlling the proliferation of endometrial cells do not interfere negatively in the positive effects of estrogens $(14,15)$. The real benefits and risks arising from hormone therapy, especially with regard to breast cancer, require an interpretation of a complex range of existing data (16, 17).

Menopausal hormone therapy or as otherwise referred to, hormone replacement therapy, has been accessible for almost 60 years $(18,19)$. For women of menopausal age, this is a treatment of choice, with main aim the management of menopause symptoms $(4,19)$. The majority of discomfort caused by menopause is due to hypoestrogenism. For this reason, hormone therapy in its early years of application was a monotherapy, consisting only of estrogen, since the symptoms of menopause were due to the complete ovarian depletion of the follicles and the lack of them $(4,19)$. However, due to the increase of endometrial hyperplasia and endometrial cancer (4) observed in the 1970s (19) among women receiving hormone therapy imposed the need for the addition of progestogen within the form of hormone therapy in order to protect the endometrium $(4,19)$.

It is stressed and noted that today, the use of hormone therapy in symptomatic women during menopause, with an average value of 51.4 years, is an acceptable option for women up to 59 years of age or within the first 10 years of menopause, taken for about 5 years and then usually discontinued, as the increase risk of breast cancer becomes apparent after 3 to 5 years of use $(12,16)$. In the 1990 s, a survey called the Women's Health Initiative (WHI), a multi-center, double-blinded placebo randomized controlled primary prevention trial, was conducted in multiple health areas in the United States of America to evaluate the health outcomes of postmenopausal women receiving longterm hormone therapy, within a period of use of 15 years, and with participants being at 50-79 years of age, with an average age of 63 years, in terms of the risk of osteoporosis, cardiovascular disease, cancer and stroke $(2,13,21)$. Few of these women had menopausal symptoms and only $3.5 \%$ of these women,

Table 2. Risk factors for breast cancer (BC) in populations with an average risk for BC (49) (excluding BRCA gene mutation)

\begin{tabular}{|c|c|c|c|}
\hline \multicolumn{2}{|l|}{$\begin{array}{l}\text { MANOSMEDGOLD INDEX (20 Parameters) } \\
\text { Factor }\end{array}$} & \multicolumn{2}{|l|}{ Relative Risk (RR) } \\
\hline 1. Age (years)* & $70-74$ & $30-34$ & 18 \\
\hline 2. BRCA gene mutation & Yes & No & 10 \\
\hline 3. Mammographic breast density & $\mathrm{d}$ & $\mathrm{a}$ & 4 \\
\hline 4. Atypical hyperplasia on breast biopsy & Yes & No & 4 \\
\hline 5. Age on first term pregnancy (years) & $>30$ & $<20$ & 3 \\
\hline 6. Nulliparity & Yes & No & 3 \\
\hline 7. Bone density (percentile) & $>75$ & $<25$ & 3 \\
\hline 8. Mother or sister with breast cancer & Yes & No & 2,6 \\
\hline 9. Age at menopause (years) & $>55$ & $<45$ & 2 \\
\hline 10. Benign condition on breast biopsy & Yes & No & 1.7 \\
\hline 11. Age at menarche (years) & $<12$ & $>14$ & 1.5 \\
\hline 12. Alcohol consumption (drinks per day) & $2-5$ & 0 & 1.4 \\
\hline 13. Current or recent use of oral contraceptives & Yes & No & 1.2 \\
\hline 14. Current use of menopausal therapy & Yes & No & 1.2 \\
\hline 15. Height $(\mathrm{cm})$ & $>175$ & $<160$ & 1.2 \\
\hline 16. Aspirin consumption ( $\geq 1 /$ week for $\geq 6$ months) & Yes & No & 0.8 \\
\hline 17. $\geq 5$ births $v s$. Nulliparity & & 0.7 & \\
\hline 18. $>16$ months of breastfeeding $v s$. no breastfeeding & & 0.7 & \\
\hline 19. Exercise & Yes & No & 0.7 \\
\hline 20. Premenopausal BMI $\geq 31$ vs. $<21 \mathrm{~kg} / \mathrm{m}^{2}$ & & 0.5 & \\
\hline
\end{tabular}


aged 50-54, had recently entered menopause (21). Due to negative effects on women's health, the research was prematurely discontinued $(7,13,21)$ after 6.8 years $(13,21)$. The main findings of the research published between 2002 and 2004 showed an increased risk of coronary heart disease $(2,4,16,21)$, breast cancer $(4$, $7,19,21)$, stroke and thromboembolic events (1) in women receiving combined hormone therapy, estrogen plus progestin, compared to placebo.

At the time when the "Women's Health Initiative" survey was conducted, the percentage of women receiving hormone therapy in the United States had reached up to $40 \%$ of women at menopause $(1,2$, $4)$. However, following the publication of the risks it could cause, the percentage decreased $(2,4)$ by up to $80 \%$ (16). The combined estrogen and progestogen hormone therapy used in this research, were conjugated equine estrogens (CEEs) with medroxyprogesterone acetate (MPA) in women with an intact uterus, and it was shown that it was triggering an increase of 24$26 \%$ in the risk of breast cancer $(2,4)$ after 5 -years of use (4). Tumors diagnosed in women who received combined hormone therapy in "WHI" were more than those in women who received placebo with an increased volume participation rate (21). This increase affected both younger and older women. The use of CEE as monotherapy in women with hysterectomy, had a significant reduction in the risk of developing breast cancer that reached $21-23 \%$ as mentioned above (2). These findings provided assurance that estrogen monotherapy would be a safe option in women with hysterectomy for a period of 7 years of use (21).

Along the way, through the results of both the "Women's Health Initiative" and other researches, it has emerged that the benefits outweigh the risk for many of these women (2). Today, it is clear that hormone replacement therapy (HRT) contributes both to the well-being and good functionality of women who have lost their reproductive capacity, as well as to the improvement and maintenance of mental and physical activity $(1,24)$, but at the same time contributes more generally to a better quality of life $(14,15)$.

\section{OBJECTIVE}

This paper aims to investigate the effects of progesterone and progestogen treatment on its relationship with the risk of breast cancer in women. Reference to other chronic conditions that hormone therapy may affect. Explanation of the various key types of hormone therapy that are administered.

\section{DESIGN}

This review which aims to investigate the possibility of breast cancer due to hormone therapy with estrogen in combination with progestogens/ progesterone, has extensive literature, and clearly has not concluded to a correlation between breast cancer and hormone therapy. What has been evident from the existing literature is the diversity of the criteria for assessing this correlation, resulting in conflicting results. Today, there is a tendency towards the widespread use of hormone therapy by the competent bodies of each country, if and as long the use of it is appropriate for each woman depending on her medical history. Personalized prescription based on each patient's unique profile and with the consent of the woman in the decision-making process.

\section{MENOPAUSE}

Menopause is a normal process that reflects complete or almost complete ovarian depletion of the follicles, leading to hypoestrogenemia and high concentration of follicle stimulating hormone (FSH), without any other apparent pathological or psychological cause. With an average incidence at 51.4 years and with life expectancy today for women being 85 years, a third of their lives, women live it in menopause, while, a small percentage of estrogen continues to be produced peripherally from adrenal androgens (26) by fat tissue. All these changes lead in the shortage of specific hormones which affects the urinary and genital system, the central nervous system, bones, skin and cardiovascular system $(14,26)$. Today hormone therapy is recommended only for the management of early menopause symptoms and not for the prevention of chronic diseases (18).

That's why in these days emphasis is placed on hormone therapy. Undoubtedly, menopausal hormone therapy is very effective in treating mild to severe menopausal symptoms $(5,7,21)$, such as vasomotor symptoms and vulvovaginal atrophy (7). CEEs are the most common method of hormone therapy, either as monotherapy or in combination with progestogens. It is commonly accepted that women who are under 60 years of age and receive hormone therapy during the first 10 years from the onset of menopause, for a period of up to 5 years, achieve short-term benefits in terms of alleviating symptoms and long-term benefits in protecting them from chronic conditions caused by menopause (7). However, over the past two decades, conflicting findings 
on the risk of breast cancer in relation to hormone therapy have been recorded by various observational surveys, thus creating a serious contrast $(4,7,21)$. The results of these studies both differ from each other in the degree of risk of developing breast cancer, if it is considered to be present depending on the combination of hormone therapy, but also in the method and the time of hormone therapy administration (21). The reason for these conflicting positions is the fact that there are multiple complex data that need to be interpreted (16).

\section{SYMPTOMS}

The distinctive features and symptoms of menopause affect $80 \%$ of women over 55 years (7) $(16,26)$ while $20 \%$ of those women exhibit severe symptoms. Because of this phenomenon, inevitably the moderate and severe symptoms of menopause, which can cause a negative impact on a woman's well-being and quality of life and health, require treatment (7). The main symptoms of menopause are vasomotor symptoms, urogenital atrophy (26), and dyspareunia. Another fact equally important is the decrease of bone density on average around $2 \%$ each year and then stabilizes at $0.5 \%$ according to Barret-Connor et al., (2005). Stroke and coronary disease are the main causes of morbidity and mortality in postmenopausal women. Estrogens promote vasodilation, reduce chronic inflammation of the vessels and create a favorable lipid profile.

\section{PROGESTERONE/ PROGESTOGENS OR PROGESTINS AND PROGESTERONE RECEPTOR}

Progestogens are hormone derivatives that have the potential to induce secretory endometrium, and to support gestation $(4,7)$. Thus, they perform an essential role in the menstrual cycle (7). However, it should be noted that chronic free exposure of endometrium to estrogen, without the compensation of progestogens, at the correct dosage, increases the risk of hyperplasia and endometrial cancer $(7,13,15)$, which is why progestogens are part of systemic hormone therapy especially in women with intact uterus $(7,26)$. The type of progesterone, the timing of its administration and the method of administration of hormone therapy has an impact on the risk of breast cancer $(4,8,18)$.

\section{Categorization of Progestogens}

It should be stressed that progestogens are divided into natural progesterone produced by the human body itself through the ovaries and adrenals and synthetic progestogens called progestins $(4,7)$. Progestins include a number of various synthetic components which are structurally related to either progesterone or testosterone, and which have potential beneficial effects on the cardiovascular and nervous system, breast and bones (7) (Table 3).

\section{Synthetic Progestogens structurally related to Progesterone}

Progestins related to progesterone are subclassified into two groups. The one is the 17 alphahydroxyprogesterone derivatives (pregnanes) and the other is 19- Norprogesterone derivatives (norpregnanes) (23), depending on the presence of a methyl group at carbon 10 (4), according to Lambrinoudaki et al. (2014).

The category of Pregnane derivatives include the non-acetylated pregnane which are dydrogesterone and medrogestone, and the acetylated pregnane derivatives which are medroxyprogesterone acetate, megestrol acetate, chlormadinone acetate and cyproterone acetate (4).

The nor-pregnane derivatives include nomegestrol acetate, nesterone, demegestone, promegestone, and trimegestone (4).

The properties of the 17 alphahydroxyprogesterone derivatives include mainly peripheral action, relatively moderate inhibition of gonadotropins, antiandrogenic effects and good tolerability.

\section{Synthetic Progestogens structurally related to Testosterone}

It is noted that this class of progestins having a relative structure with testosterone are divided into ethinylated compounds and non-ethinylated compounds such as dienogest and drospirenone (4).

Ethylated derivatives are subclassified into 19- nor-testosterone derivatives (estranes) such as norethisterone acetate, norethyndronel, ethynodiol diacetate and lynestrenol, and in 13-ethylgonanes, consisting of levonorgestrel, desogestrel, norgestimate and gestodene (4).

Properties of 19-nortestosterone derivatives include high bioavailability and strong progestational effects on the endometrium (15) and antigonadotropic effect when given at least 15 days per cycle. They also have mild androgenic action and rapid absorption, while ethylgonans are more powerful than estranes with less androgenic action. 
Synthetic progestins, as all synthetic progesterone are called (7), have a different chemical structure than the female-produced progesterone. Although their components mimic some of the behaviors of progesterone, they have a different effect on progesterone receptors. Synthetic progesterones may have a structural affinity with progesterone but they have different potency and pharmacokinetic properties. Therefore, the physiological effects of certain progesterones depend not only on their properties, but also on their bonding with their receptors (5). There is also an association which is statistically significant with the use of combined hormone therapy and tumors with positive ER+ PR+. With a greater likelihood of lobular cancer, with the OR in some studies at $2.84(10,18)$.

\section{HORMONE REPLACEMENT THERAPY}

Hormone therapy or menopausal hormone therapy, or hormone replacement therapy, is a broad term describing estrogen monotherapy in women who have undergone hysterectomy and combined estrogenprogesterone/ progestogens therapy in women with an intact uterus (26), as well as other hormone therapy options (27). Estrogen therapy achieves the discharge of almost all menopausal symptoms such as vasomotor symptoms, which are associated with sleep, concentration disorders, reduced quality of life, urogenital atrophy $(7,26)$ up to the long-term prevention of chronic diseases whose direct association with lack of estrogen is not immediately visible (4).

\section{Benefits of Hormone Replacement Therapy}

Apart the side effects and risks that are likely to occur, HRT also offers significant benefits. For example, cardiovascular diseases are the primary cause of death for women, especially as they are getting older. In clinical observational studies, HRT contributes to the delay of atherosclerotic cardiovascular diseases, and to the improvement of lipid profile $(2,4,16,26)$. Based

Table 3. Classification of progestogens (4)

\section{Natural progestogens}

\section{Synthetic progestogens (progestins)}

\subsection{Structurally related to progesterone}

2.1.1 17a- Hydroxyprogesterone derivatives (pregnanes)

2.1.1.1 Acetylated

2.1.1.2 Non- acetylate

2.1.2 19 Nor- progesterone derivatives (nor-pregnanes)

\subsection{Structurally related to testosterone}

\subsubsection{Ethinylated derivatives}

2.2.1.1 19 Nortestosterone derivatives (estranes)

2.2.1.2 19 Nortestosterone derivatives (19- ethylgonanes)

\subsubsection{Non-ethinylated derivatives}

Progesterone

Dydrogesterone
Medroxyprogesterone acetate (MPA)

Megestrol acetate

Chlormadinone acetate

Cyproterone acetate

Medrogestone

Nomegestrol acetate

Nesterone

Demegeston

Promegestone

Trimegestone

Norethisterone acetate (NETA)

Ethynodiol diacetate

Norethyndronel

Lysterenol

Levonorgestrel

Desogestrel

Gestodene

Norgestimate

Dienogest

Drospirenone 
on randomized clinical studies such as the "WHI" and Heart and Estrogen/ progestin Replacement Study (HERS), combined hormone therapy reduces insulin resistance, delaying and reducing the risk of developing type 2 diabetes, without having any effect on the incidence of cardiovascular disease $(4,26)$. Hormone therapy works beneficially in the cardiovascular system before the appearance of advanced atherosclerosis.

\section{Hormone therapy Risks and Contraindications}

Hormone therapy, although is a safe option for healthy symptomatic women (12), has absolute and relevant contraindications. Absolute contraindications of HRT are undiagnosed vaginal bleeding, breast cancer, especially in women with an individual history, as women with a family history can receive treatment but have a higher basic risk than women without a family history, endometrial cancer, thromboembolic disease, stroke, myocardial infarction, transient ischemic episode and active liver disease or dysfunction (26, 27). Oral estrogen should be avoided in women with hypertriglyceridaemia, active gallbladder disease, and known thrombophilia as lack of factor V Leiden (26) or VIII Willebrandt. Relevant contraindications are hypertension, increased cholesterol LDL, triglycerides in the serum, hypothyroidism, ovarian cancer, S.L.E, severe hypocalcemia, epilepsy, liver hemangioma, porphyria, endometriosis, asthma and migraine $(26,27)$.

Having side effects and risks, we have to decide the type of estrogen to be administered, the route of administration, and whether or not the need for co-administration of progestogen, finding the safest derivative for each woman $(26,27)$. The type and manner of treatment may reduce some of these risks.

\section{Combined therapy of estrogens and progestogens}

It should be stressed that the use of a combined therapy of estrogen with progestogens as hormone treatment for women of menopausal age should be performed in accordance with national and international guidelines. The type, dose, method of administration and duration for taking progestogens depends on the type and dose of estrogen administered in association with the efficacy of progestogens on the endometrium (7). At the same time, the metabolic profile and the tolerability of progestogens should be considered according to the specific risk factors of a hormone therapy for each patient (7) (Table 4).

\section{Route of Administration}

Most progestogens are administered per os $(3,7)$. Progesterone can, however, be administered directly to the endometrium via intrauterine device, an intrauterine hormone release formulation (LNG-IUS) (3). Estrogens can be administered in many forms, most often administered orally and transdermally. All routes of administration are effective for relieving vasomotor symptoms $(4,8,22,26)$. However, their metabolic effect differs (26). It is noted that even vaginal estrogens, which exert local action and are more effective in alleviating the symptoms of urogenital atrophy, a part of them is systematically absorbed (21). So, high doses of vaginal estrogen can also be used to treat vasomotor symptoms much like a transdermal preparation, but this is not recommended (26). But the breast cancer risk appears to vary with different modes of delivery. Woman who used transdermal form do not have an increased risk for breast cancer due to differences in pharmacokinetics and pharmacodynamics between the two forms (8).

\section{Beginning and stopping hormone therapy}

In March 2015, the European Menopausal Society (EMAS) declared its position on HRT through a 10-point guide to integrated menopause management. These points are based on: 1st taking a right medical history, individual and family history, and clinical examination, $2^{\text {nd }}$ diagnosis of menopausal status, e.g. premature ovarian failure, $3^{\text {rd }}$ modification of the diet and lifestyle change, $4^{\text {th }}$ women should take part in population control programs for diseases in later life, e.g. screening for cervical, breast, bowel cancer, $5^{\text {th }}$ control of vasomotor symptoms with or without estrogen intake. Emphasizing that HRT should be prescribed to symptomatic women under 60 years of age or within the first 10 years of menopause, as then the benefit outweighs the risk. $6^{\text {th }}$ the use of estrogen locally, at a low dose, is recommended when there are symptoms from the urogenital system only, $7^{\text {th }}$ protection of the musculoskeletal system and reduced risk of osteoporotic fractures and bone loss using HRT as well as SERM'S, $8^{\text {th }}$. in women with premature ovarian insufficiency we have to administrate HRT until they reach the normal age of menopause, unless there is a contraindication, $9^{\text {th }}$ contraception in perimenopause and $10^{\text {th }}$ continuous monitoring and reassessment (33).

\section{Dose of administration}

In the past there was the theory that "one -sizefits all". Thus, when the woman was relieved of the 
symptoms, the same dose continued indefinitely (26). Today, the most appropriate dosage of hormone therapy depends on the hormonal phase of the woman, her age, and her general health status (26). There are guidelines for starting treatment and then the treatment adjusts according to the needs of each patient individually (12, 26). Usually, a treatment begins with a low dose and slowly increases until we reach the lowest dosage that will relieve the symptoms of each woman $(3,7,26,33)$.

For perimenopausal women or newly menopause we initiate cyclic administration of oral micronized progesterone $200 \mathrm{mg} /$ day for 12 days of each calendar month. As the continuous administration in these women is associated with irregular, unscheduled bleeding due to the exogenous hormones and the continuous production of hormones endogenously from the ovaries. For menopausal women we administered a continuous regimen of micronized progesterone $100 \mathrm{mg} /$ day. Micronized progesterone is a biological hormone with a molecular structure identical to the endogenous progesterone produced by the ovaries. We assume that it may not be associated with an increased risk of breast cancer and also offers endometrial protection. The most commonly prescribed synthetic progestin historically and the most studied is medroxyprogesterone acetate (MPA). It can be given cyclic $5-10 \mathrm{mg}$ / day or continuous $1.25-2.5$ $\mathrm{mg} /$ day regimen. Several studies have confirmed that taking it is associated with an increased risk of breast cancer, as in "WHI" study $(9,15)$. Women who do not tolerate oral progesterone have the option of placing Levonorgestrel-leasing intrauterine device-LNG-IUS in the endometrium. It protects the endometrium in women who take estrogen either orally or transdermal, and almost all women develop a non-proliferative atrophic endometrium. Another progestogen that can be used is Norethisterone acetate, which is administered orally cyclic at a dose of $5-10 \mathrm{mg} /$ day and continuously 0.5 or 0.7 or $1 \mathrm{mg} /$ day. This progesterone is equally effective for relieving vasomotor symptoms and preventing intrauterine hyperplasia but it was associated with an increased risk of breast cancer (9, 27). Other progestogens include Dydrogesterone which is administered cyclic 10-20 mg /day and continuously $5 \mathrm{mg} /$ day. Megestrol acetate is administered cyclic at the $2.5-10 \mathrm{mg} /$ day dose.

\section{Factors that modify breast cancer risk}

The risk of developing breast cancer has several risk factors that contribute to its appearance. The known risk factors are: 1 . Increasing age, 2. Female gender, breast cancer occurs 100 times more frequently in women than in man. 3. Race, more common in white race. 4. High estrogen levels, such as estrogendependent tumors, early menarche before the age of 12 years, and delayed menopause after 55 years, nulliparous

Table 4. Type and dose of progestogens and estradiol in fixed commercial products in Finland (9)

\begin{tabular}{|c|c|c|}
\hline Regimen & Dose of progestogen $(\mathrm{mg})$ & Dose of estradiol (mg) \\
\hline \multicolumn{3}{|c|}{ Sequential estradiol-progestogen therapy, type of progestogen } \\
\hline \multicolumn{3}{|c|}{ Oral } \\
\hline Norethisterone acetate & 1 & 1 or 2 \\
\hline Medroxyprogesterone acetate & 10 & 2 \\
\hline Medroxyprogesterone acetate ${ }^{1}$ & 20 & 2 \\
\hline Levonorgestrel & 0.25 & 2 \\
\hline \multirow[t]{2}{*}{ Dydrogesterone } & 10 & 1 门́ 2 \\
\hline & 20 & 2 \\
\hline Trimegestone & 0.5 & 2 \\
\hline \multicolumn{3}{|l|}{ Transdermal } \\
\hline \multirow[t]{2}{*}{ Norethisterone acetate } & 0.17 ฑ́ 0.25 & 0.05 \\
\hline & 0.01 & 0.05 \\
\hline Levonorgestrel & 0.02 & 0.065 \\
\hline \multirow{2}{*}{\multicolumn{3}{|c|}{ Continuous estradiol-progestogen therapy, type of progestogen }} \\
\hline & & \\
\hline & 0.5 & 1 \\
\hline \multirow[t]{2}{*}{ Norethisterone acetate } & 1 ク́ 0.7 & 2 \\
\hline & 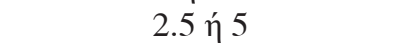 & 1 \\
\hline Medroxyprogesterone acetate & 5 & 2 \\
\hline Dydrogesterone & 5 & 1 \\
\hline Drospirenone & 2 & 1 \\
\hline \multicolumn{3}{|l|}{ Transdermal } \\
\hline Norethisterone acetate & 0.17 ஸ́ 0.25 & 0.05 \\
\hline
\end{tabular}

${ }^{1}$ Long cycle, progestogen for 14 days every $3^{\text {rd }}$ month. 
woman, postmenopausal obesity, increase age at first pregnancy, no or breast feeding less than 12 months, alcohol intake, smoking. The relationship between estrogen and breast cancer risk is confirmed by data, in a variety of animal systems and by epidemiological data in women, with estrogen having a key role in breast cancer risk $(21,25)$. 5. History of benign breast disease, especially in cases where histologic atypia is present, increases the risk. 6 . Increased breast density, women with mammographic dense breast have a $4-5$ times higher risk for breast cancer $(15,32)$, compared to women of the same age with less or no mammographic dense breast. 7. The family history of breast cancer in first-degree relatives in cases where it occurred at a young age and in the number of first-degree female relatives who experienced it (34). 8. The personal history of breast cancer. 9. Inherited mutations that predispose to breast cancer are rare, with only 5-6\% of all breast cancers. The susceptibility genes are BRCA1, BRCA2, p53, STK11, CDH1, PALB2, PTEN and the mismatch repair genes. Short-term hormone therapy is not associated with a significant increase in the risk of breast cancer $(4,34,39)$.

\section{Other hormone preparations}

\section{Tibolone}

Tibolone is a synthetic steroid preparation, classified as a selective tissue estrogen activity regulator (STEAR), having differential actions depending on the target organ $(3,8)$. It has a beneficial effect on bone mineral density and effects on libido (27). It has an estrogenic effect mainly on bones, brain, vagina, avoiding undesirable effects on the breast and endometrium, even reducing the density of the breasts. Recent in vivo studies have also demonstrated evidence that tibolone stimulates apoptosis and inhibits cell proliferation on breast cancer cells $(4,8)$. This synthetic steroid has metabolites which have estrogenic, weak androgenic and progestogenic properties. It also reduces vasomotor symptoms when compared to placebo, but is less effective than estrogen therapy (27). The recommended daily dosage is $2.5 \mathrm{mg}$ and is taken in oral tablet form (4).

\section{Conjugated estrogen with Bazedoxifene}

Another alternative treatment is the combined treatment of conjugated equine estrogens (CEE) and SERM's- Selective Estrogen Receptor Modulator, Bazedoxifene, which is available in the USA (Duavee), for the treatment of menopausal vasomotor symptoms and the prevention of osteoporosis $(13,26,27)$. This combination prevents the action of estrogen in the endometrium, acting as an antagonist of estrogen receptors in the uterus, so that administering a progestin is not needed $(13,27)$. Candidates are women with moderate to severe hot flashes, who have breast tenderness by taking standard combined estrogenprogestin hormone therapy or for women who do not tolerate any type of progesterone due to its side effects (34). Like all SERM's, they have an increased risk for venous thromboembolic events and stroke $(26,27)$.

\section{Mechanisms of breast carcinogenesis}

Normal mammary growth, differentiation and regression is the results of complex interactions between systemic hormones and local interactions between cells (37). These interactions are mediated by a variety of growth factors, including epidermal growth factor, transforming growth factor, insulin growth factor and fibroblast growth factor. The morphologic response of the breast to these complex interactions results in changes in development which permanently modifies both the architecture and biologic characteristics of the breast (37). The process of differentiation of the mammary gland is the result of complex interactions that cause inhibition of cell proliferation, reduction of the regulatory capacity of ER/PR and activation of specific genes. Breast cancer occurs only in women whose breast does not have the optimal degree of differentiation (37).

\section{Progesterone / Progestogen}

Normal breast development requires the presence of estrogen and progesterone. Progesterone acts in synergy with estrogen to regulate breast development through a specific receptor (PR) on the breast epithelial cells. As regards the role of progestogens in mammary carcinogenesis, is less clear, as cell culture and animal experiments show that it can have proliferative effects, be neutral or have antiproliferative effects $(21,22,37)$. We stress that the action of progestogens on the breast is complex and not fully understood $(21,22)$. The mechanisms by which they act on cell proliferation include interaction with steroid receptors, growth factors, oncogenes and estrogen metabolizing enzymes (22). Progesterone used alone is not associated with an increased risk of breast cancer (8). In vivo and in vitro studies have demonstrated both antagonistic and synergistic effects of progesterone in the presence of estrogen. One possible hypothesis is that progesterone may increase the multiplier effect of estrogen on the breast, but further research is needed (8). 
The action of progestogens in the postmenopausal breast is also not fully understood (25). Because progestogens differ widely in their chemical structure, metabolism, pharmacokinetics and potency, it makes sense to cause different responses in the breast (22). The effects of progestogens vary according to the hormone with which they are co-administered, with the duration of treatment, and dose concentration. As a result, it is impossible to establish, on our so far available and conflicting in vitro data, whether the predominant effect of a given progestogen is to stimulate or inhibit breast cell proliferation $(22,25)$. Mitotic index and nuclear antigen cell index are reduced using estrogen/ natural progesterone and increase significantly with the use of CEE/medroxyprogesterone acetate (MPA) $(15,21)$. Indeed, in vitro evidence suggests the proliferative effect of MPA on the breast tissue. Furthermore, the terminal duct lobular unit from which we believe the onset of cancer initiation, is stimulated to a greater extent by MPA/CEE than only CEE alone in menopausal women (21). This is why the safety of natural micronized progesterone is recommended compared to MPA in the menopausal mammary gland (13). The effect of progestins on breast cancer tumorigenesis may depend on the specific progesterone used for HRT The interaction between hormone use and progression of breast cancer may be explained by progestin -mediated effects (12).

\section{RESULTS}

In detail, for each survey individually, it should be noted that all the surveys used a large number of samples, except for the Norman et al., (2010) survey, which used around 5 thousand subjects.

In terms of the age of the survey participants, there was a variation in their age. Norman et al., (2010) and Simin et al., (2017) used participants aged between 35 and 40 years, Antoine et al., (2015) used as a sample participants 45 years old, 50 years old, and Lyytinen et al., (2009), Calle et al., (2009), Opatrny et al., (2008) Jick et al., (2009) and Fournier et al. (2007) used participants 50 years old, which was also the limit of most surveys. A similar variation existed in the age limit that allowed a woman to be included in a survey, starting with the maximum age of 64 set by Norman $e t$ al., (2010), reaching the age of 70-74 years that Calle et al., (2009) had.

As for the type of hormone therapy, there was also a difference in the medicinal preparations used. Norman et al., (2010), Calle et al., (2009) and
Antoine et al., (2015), in addition to the reference of estrogen and progestogens they do not name the type of formulations that represent each category as opposed to Lyytinen et al., (2009) and Opatrny et al., (2008) which analyzed both the exact type of estrogen and the type of progestogens. The Opatrny et al., (2008) went further, comparing the degree of the risk for breast cancer in terms of how hormone therapy was taken, i.e. whether it was transdermal or oral and whether the intake was continuous or sequential. While the research of Jick et al., (2009) determined only the type of progesterone. Finally, the research of Fournier et al. named the type of estrogen and progestogens that increase or not the risk of breast cancer and the estimated length of time that the various combinations of hormone therapy increase the risk of breast cancer.

Regarding the association between the use of hormone therapy and the possible increased risk of developing breast cancer, Norman et al., (2010) found an increased risk for current $3+$ years users (CIs 1.38) with combined hormone therapy. The research of Simin et al., (2017) argues that the use of hormone therapy, and in particular the combination of estrogen with progestogens, carries a limited increased risk for breast cancer (SIR 1.14). Also the risk of breast cancer with combined hormone therapy was greater with the continued use (SIR 1.6). According to the above research, the same position was supported by the research of Jick et al., (2009) where they determine the risk from combined hormone therapy (OR 1.44). The risk was higher after the first 4 years of intake, being three times greater, than in women who have never been exposed to hormone therapy. Researchers of the Lyytinen et al. survey, (2009) and Opatrny et al., (2008), become more specific showing a correlation between hormone therapy and breast cancer, but not in all cases and not in the same association. There are combinations that increase the risk and some other combinations that do not show an increase in risk. More specifically, in Lyytinen et al., (2009), the combined hormone therapy is associated with an increased risk for breast cancer as early as three years of its use. With its continued use also being associated with an increase in the risk of breast cancer, compared to sequential, and that was also confirmed by Simin et al. with the OR for continued combined hormone therapy to be 1.6. There are also differences in the risk of breast cancer which depend on the type of hormone therapy. The use of tibolone and LNG-IUS alone was also associated with an increased risk of breast cancer. The same applies to Opatrny et al., (2008), who agreed that women who were receiving 
hormone therapy and subsequently received tibolone were at risk for breast cancer. In Calle et al. survey, (2009) there is a clear distinction between the degree of risk on various forms of hormone therapy, the two major histological types of breast cancer, the extent of the disease, and the estrogen-progesterone receptors. It also indicated that there is no increased risk for ductal breast cancer in recent estrogen monotherapy recipients even after 20 years of use, while there is an increased risk (approximately 50\%) of lobular breast cancer with estrogen monotherapy recipients for use up to 10 years or more. Finally, in the research of Fournier et al. (2007), the combination of estrogen with progesterone or dydrogesterone was associated with no or less and non-statistically significant increase in the risk of breast cancer, while the combination of estrogen with other progestogens, even for a short time of use ( $<2$ years), was associated with a significant 1.36 times increase in the risk of breast cancer. For any combination of estrogen-progestogens, the route of administration of estrogen had no statistically significant difference in terms of risk for breast cancer. Women who never used HRT, compared to women who used combined hormone therapy with other progestogens, had an increased risk for breast cancer, with the second group significantly at greater risk, demonstrating that by adding specific progestins to estrogen increases the adverse effect on the risk of breast cancer.

In conclusion, in the future, more research should be carried out to deal with specific doses of estrogen and progestogens, alone or in combination, as well as the type of progestogen and estrogen satiated, which will be administered in order to compare and find the least possible dose and combination of hormone therapy which increase the risk for developing breast cancer. Through the systematic review of the literature carried out, some basic conclusions have emerged, which in some cases are conflicting with each other and therefore require further scientific research to conclude in more consistent results. To sum up, combined hormone therapy was associated with an increased risk for breast cancer. The risk was directly proportional to the duration of use, and in some studies the risk increased from the first 3 years of its use. Depending on progesterone or progestogen, several studies have agreed that natural micronized progesterone and dydrogesterone was associated with a lower to zero risk for breast cancer, compared to other progestogens, while, the risk increased significantly for testosteronerelated progestogens, rather than progesterone - related progestogens. As regards the method of administration, the continued use of combinedhormone therapyincreased the risk of breast cancer, compared to sequential use. The route of administration of hormone therapy, e.g. oral, vaginal, transdermal, did not differentiate the risk of breast cancer. The risk of breast cancer increases as a woman's age increases, with all research agreeing to administer hormone therapy up to the age of 59 years or within the first ten years of menopause. Some research also suggests that women with initiation of HRT in the immediate menopausal period have an increased risk for breast cancer, compared to women who delay taking it for at least one year. In addition, the risk of breast cancer was higher in women who were previously receiving hormone therapy and later received a new regimen of hormone therapy, while, in non-recent use of hormone therapy, the risk for breast cancer which was associated with hormone therapy disappears when women stop receiving it. It was observed that women with a normal body mass index $\left(\mathrm{BMI}<25 \mathrm{~kg} / \mathrm{m}^{2}\right)$ in menopause have an increased risk for breast cancer by using hormone therapy. In addition, hormone therapy recipients had a higher rate for tumors with positive estrogenic and progesterone receptors, a finding associated with positive clinical outcomes. Hormone therapy used to be strongly associated with lobular histological type of breast cancer. At the end, in several European countries no evidence was found between breast cancer cases and sales of hormone therapy.

\section{Conflict of interest}

The authors declare that they have no conflict of interest.

\section{References}

1. Manson JAE, Chlebowski RT, Stefanick ML, Aragaki AK, Rossouw JE, Prentice RL, Anderson G, Howard BV, Thomson CA, LaCroix AZ, Wactawski-Wende J, Jackson RD, Limacher M, Margolis KL, Wassertheil- Smoller S, Beresford SA, Cauley JA, Eaton CB, Gass M, Hsia J, Johnson KC, Kooperberg C, Kuller LH, Lewis CE, Liu S, Martin LW, Ockene JK, O 'Sullivan MJ, Powell LH, Simon MS, Van HL, Vitolins MZ, Wallace RB. The Women's Health Initiative Hormone Therapy Trials: Update and Overview of Health Outcomes During the Intervention and PostStopping Phases. National Institutes of Health, JAMA. 2013; 310 (13): 1353-1368.

2. Bassuk SS, Manson JAE. Oral Contraceptives and Menopausal Hormone Therapy: Relative and Attributable Risks of Cardiovascular Disease, Cancer, and Other Health Outcomes. Annals Epidemiology. 2015; 25(3): 193-200.

3. Fait T. Menopause hormone therapy: latest developments and clinical practice. Drugs in Context. 2019; 8: 1-9.

4. Lambrinoudaki I. Progestogens in postmenopausal hormone therapy and the risk of breast cancer. Maturitas. 2014; 77 (4): 311317. 
5. Asi N, Mohammed K, Haydour Q, Gionfriddo MR, Vargas Morey OL, Prokop LJ, Faubion SS, Murad MH. Progesterone vs. synthetic progestins and the risk of breast cancer: a systematic review and meta-analysis. Systematic Reviews. 2016; 5 (1): 121129.

6. Norman SA, Weber AL, Localio AR, Marchbanks PA, Ursin G, Strom BL, Weiss LK, Burkman RT, Bernstein L, Deapen DM, Folger SG, Simon MS, Nadel MR. Hormone Therapy and Fatal Breast Cancer. Pharmacoepidemiology Drug Safety. 2010: 19(5): 440-447.

7. Palacios S, Stevenson JC, Schaudig K, Lukasiewicz M, Graziottin A. Hormone therapy for first-line management of menopausal symptoms: Practical recommendations. Women's Health. 2019; 15: $1-8$.

8. Opatrny L, Aniello SD, Assouline S, Suissa S. Hormone replacement therapy use and variations in the risk of breast cancer. General gynaecology BJOG. 2008; 115 (2): 169-175.

9. Lyytinen HK, Dyba T, Ylikorkala O, Pukkala EI. A case-control study on hormone therapy as a risk factor for breast cancer in Finland: intrauterine system carries a risk as well. International Journal of Cancer. 2010; 126 (2): 483-489.

10. Calle EE, Feigelson HS, Hildebrand JS, Teras LR, Thun MJ, Rodriguez C. Postmenopausal Hormone Use and Breast Cancer Associations Differ by Hormone Regimen and Histologic Subtype. Cancer. 2009; 115 (5): 936-945.

11. Jick SS, Hagberg KW, Kaye JA, Jick H. Postmenopausal Estrogen-Containing Hormone Therapy and the Risk of Breast Cancer. Obstetrics \& Gynecology. 2009; 113(1): 74-80.

12. Gurney EP, Nachtigall MJ, Nchtigall LE, Naftolin F. The Women's health Initiative trial and related studies: 10 years later: A clinician's view. Journal of Steroid Biochemistry \& Molecular Biology. 2014; 142: 4-11.

13. Ghazal S, Pal L. Perspective on hormone therapy 10 years after WHI. Maturitas. 2013; 76 (3): 208-212.

14. Schindler AE. The "newer" progestogens and postmenopausal hormone therapy (HRT). Journal of Steroid Biochemistry \& Molecular Biology. 2013; 142: 48-51.

15. Mirkin S. Evidence on the use of progesterone in menopausal hormone therapy. Climacteric. 2018; 21 (4): 346 - 354.

16. Santen RJ, Allred DC, Ardoin SP, Archer DF, Boyd N, Braunstein GD, Burger HG, Colditz GA, Davis SR, Gambacciani M, Gower BA, Henderson VW, Jarjour WN, Karas RH, Kleerekoper M, Lobo RA, Manson EJ, Marsden J, Martin AK, Martin L, Pinkerton VJ, Rubinow RD, Teede H, Thiboutot MD, Utian HW. Executive Summary: Postmenopausal Hormone Therapy: An Endocrine Society Scientific Statement. Journal of Clinical Endocrinology Metabolism. 2010; 95(1): 1-65.

17. Schmitz HK, Williams IN, Kontos D, Domchek S, Morales HK, Hwang TW, Grant LL, DiGiovanni L, Salvatore D, Fenderson D, Schanail M, Galantino ML, Stopfer J, Kurzer MS, Wu S, Adelman J, Brown JC, Good J. Dose-response effects of aerobic exercise on estrogen among women at high risk for breast cancer: a randomized controlled trial. Breast Cancer Research \& Treatment. 2018; 154 (2): 309-318.

18. Simin J, Tamimi R, Lagergren J, Adami HO, Brusselaers N. Menopausal hormone therapy and cancer risk: An overestimated risk? European Journal of Cancer. 2017; 84: 60-68.

19. Duverger-Cordina E, Truong T, Anger A, Sanchez M, Arveux P, Kerbrat P, Guenel P. Risk of Breast Cancer by Type of Menopausal Hormone Therapy: a Case-Control Study among Post-Menopausal Women in France. PLOS ONE. 2013 ;8 (11): 1-9.

20. Prior JC. Progesterone for treatment of symptomatic menopausal women. Climacteric. 2018; 21 (4): 358-365.

21. Santen RJ. Menopausal hormone therapy and breast cancer. Journal of Steroid Biochemistry \& Molecular Biology. 2013; 142: $52-61$.

22. Fournier A, Berrino F, Clavel-Chapelon F. Unequal risks for breast cancer associated with different hormone replacement therapies: results from the E3N cohort study. Breast Cancer Res Treat. $2008 ; 107$ (1): 103-111.

23. Antoine C, Ameye L, Paesmans M, Azambuja E, Rozenberg S. "Menopausal Hormone Therapy use in Relation to Breast Cancer Incidence in 11 European Countries," Maturitas. 2016; 84: 81-88.

24. Rohan TE, Negassa A, Chlebowski RT, Lasser NL, McTiernan A, Schenken RS, Ginsberg M, Wassertheil-Smoller S. Page D. L.: "Estrogen plus Progestin and Risk of Benign Proliferative Breast Disease," National Institutes of Health. Cancer Epidemiol Biomarkers Prev. 2008; 17 (9): 2337-2343.

25. Newcomb PA, Titus-Ernstoff L, Egan KM, Trentham-Dietz A, Baron JA, Storer BE, Willett WC, Stampfer MJ. Postmenopausal Estrogen and Progestin Use in Relation to Breast Cancer Risk. Cancer Epidemiology, Biomarkers \& Prevention. 2002; 11: 593600.

26. Martin KA, Barbieri RL, Snyder PJ, Crowley WF, Mulder JE. Treatment of Menopausal symptoms with hormone therapy. Up to Date 2020.

27. Martin KA, Barbieri RL, Snyder PJ, Crowley WF, Mulder JE. Preparation for menopausal hormone therapy. Up to Date 2019.

28. Lyytinen H, Pukkala E, Yikorkala O. Breast Cancer Risk in Postmenopausal Women Using Estradiol- Progestogen Therapy. Obstet Gynecol. 2009; 113 (1): 65-73.

29. de Villiers TJ, Hall JE, Pinkerton JV, Cerdas Perez S, Rees M, Yang C, Pierroz DD. Revised Global Consensus Statement on Menopausal Hormone Therapy Climacteric. 2016; 19 (4): 313-315. 30. Chen WY, Barbieri RL, Crowley WF, Elmore JG, Martin KA. Menopausal hormone therapy and the risk for breast cancer. Up to Date 2018.

31. Chen WY, Manson J E, Hankinson SE, Rosner B, Holmes M D, Willett WC, Colditz GA. Unopposed Estrogen Therapy and the Risk of Invasive Breast Cancer. Archive of International Med. 2006; 166 (9): 1027-1032.

32. Cobin RH, Goodman NF. On behalf of the AACE Reproductive Endocrinology Scientific Committee. American association of clinical endocrinologists and American College of Endocrinology position statement on menopause. Up to Date 2017.

33. Neves-e- Castro M, Birkhauser M, Samsioe G, Lambrinoudaki I, Palacios S, Borrego SR, Llaneza P, Ceausu I, Depypere H, Tamer Erel C, Perez-Lopez FR, Schenck- Gustafsson K, van der Schouw YT, Simoncini T, Tremollieres F, Rees M. EMAS position statement: The ten point guide to the integral management of menopausal health, Maturitas. 2015; 81 (1): 88-92.

34. Chen WY, Chagpar AB, Hayes DF, Vora SR. Factors that modify breast cancer risk in women. Up to Date 2019.

35. Pinkerton VJ, Sanchez FA, Blake J, Cosman F, Hodis N H, Hoffstetter S, Kaunitz MA, Kingsberg AS, Maki MP, Manson E J, Marchbanks P, McClung RM, Nachtigall EL, Nelson ML, Pace TD, Sarrel MP, Shifren LJ, Stuenkel AC, Utian HW. The 2017 hormone therapy position statement of the North American Menopause Society. Menopause: The Journal of The North American Menopause Society. 2017; 24 (7): 728-753.

36. Joe BN, Burstein HJ, Vora S R. Clinical features, diagnosis and staging of newly diagnosed breast cancer. Up to Date 2020.

37. Russo J, Chagrar AB, Chen W. Breast development and morphology. Up to Date 2019.

38. Zervoudis S, Iatrakis G, Peitsidis P, Tsikouras P, Galazios G, Liberis V, Navrozoglou I, Ceausu I, Badiu C. Tibolone Vaginal Versus Per os Administration in the Management of Postmenopausal Symptoms. Rev Med Chir Soc Med Nat Iasi. 2009; 113 (2): 471-477.

39. Iatrakis G, Daures JP, Geahchan N, Maudelonde T, Bothou A, Chraibi C, Omar O, Voiculescu S, Antoniou E, Youseff T, Tsikouras P, Galazios G, Chalazonitis A, Zervoudis S. Manosmed University Risk factor calculator for female breast cancer: preliminary data. Review Clinical Pharmacology and Pharmacokinetics. 2018; 32: 23-27. 